九州大学学術情報リポジトリ

Kyushu University Institutional Repository

唾液腺基底細胞腺腫と類似腫瘍におけるWnt $/ \beta$ cateninシグナル経路異常とその診断的有用性

佐藤，方宣

http://hdl. hand le. net/2324/1937171

出版情報：Kyushu University，2018，博士（医学），課程博士 バージョン：

権利関係 : ๑ 2018 Elsevier GmbH. 


\title{
Wnt/ $\beta$-catenin signal alteration and its diagnostic utility in basal cell adenoma and histologically similar tumors of the salivary gland
}

\author{
Masanobu Sato $^{\mathrm{a}}$, Hidetaka Yamamoto ${ }^{\mathrm{a}}$, Yui Hatanaka ${ }^{\mathrm{a}}$, Toshimitsu Nishijima ${ }^{\mathrm{b}}$, Rina Jiromaru ${ }^{\mathrm{a}}$, \\ Ryuji Yasumatsu ${ }^{\mathrm{c}}$, Kenichi Taguchi ${ }^{\mathrm{d}}$, Muneyuki Masuda ${ }^{\mathrm{e}}$, Takashi Nakagawa ${ }^{\mathrm{c}}$, Yoshinao Oda, ${ }^{\mathrm{a}, *}$ \\ ${ }^{a}$ Department of Anatomic Pathology, Graduate School of Medical Sciences, Kyushu University, 3-1-1 Maidashi, Higashi-ku, Fukuoka-shi, Fukuoka, 812-8582, Japan \\ ${ }^{\mathbf{b}}$ Department of Otorhinolaryngology, Japan Community Health Care Organization Kyushu Hospital, 1-8-1 Kishinoura, Yahatanishi-ku, Kitakyushu-shi, Fukuoka, 806- \\ 8501, Japan \\ ${ }^{c}$ Department of Otorhinolaryngology, Graduate School of Medical Sciences, Kyushu University, 3-1-1 Maidashi, Higashi-ku, Fukuoka-shi, Fukuoka, 812-8582, Japan \\ d Department of Pathology, National Kyushu Cancer Center, 3-1-1 Notame, Minami-ku, Fukuoka-shi, Fukuoka, 811-1395, Japan \\ e Department of Head and Neck Surgery, National Kyushu Cancer Center, 3-1-1 Notame, Minami-ku, Fukuoka-shi, Fukuoka, 811-1395, Japan
}

\section{A R T I C L E I N F O}

\section{Keywords:}

Basal cell adenoma

Adenoid cystic carcinoma

Salivary gland

$\beta$-catenin

$A P C$

AXIN

\begin{abstract}
A B S T R A C T
Differential diagnosis among basal cell adenoma (BCA), basal cell adenocarcinoma (BCAC), adenoid cystic carcinoma (ACC) and pleomorphic adenoma (PA) of the salivary gland can be challenging due to their similar histological appearance. Although frequent nuclear $\beta$-catenin expression and CTNNB1 mutations have been reported in BCA, further details of the Wnt/ $\beta$-catenin signal alterations are unclear. The aim of this study was to assess the diagnostic utility of Wnt/ $\beta$-catenin signal alteration in BCA and morphological mimics. We performed immunohistochemical staining for $\beta$-catenin and mutation analysis for Wnt/ $\beta$-catenin-related genes (CTNNB1, APC, AXIN1 and AXIN2) in BCA $(\mathrm{n}=34)$, BCAC $(\mathrm{n}=3)$, ACC $(\mathrm{n}=67)$ and PA $(\mathrm{n}=31)$. We also analyzed ACCspecific $M Y B$ and MYBL1 gene rearrangements by fluorescence in situ hybridization (FISH). Nuclear $\beta$-catenin expression $(\geq 3 \%$ ) was present in $32 / 34$ cases $(94.1 \%$ ) of BCA, and the nuclear $\beta$-catenin labeling index was significantly higher than in other tumor types $(\mathrm{p}=<0.0001)$. In BCA, we found mutations in CTNNB1, APC and AXIN1 genes (41.1\%, 2.9\% and 8.8\%, respectively). In BCAC, nuclear $\beta$-catenin expression with CTNNB1 mutation was present in $1 / 3$ cases (33.3\%). As for ACC, nuclear $\beta$-catenin expression was observed in 3/67 cases (4.4\%), but all 3 cases harbored either $M Y B$ or $M Y B L 1$ gene rearrangement. The results suggest that nuclear $\beta$ catenin immunoreactivity with appropriate criteria may be helpful to distinguish BCA from histologically similar tumors. However, a minor subset of ACCs with nuclear $\beta$-catenin expression require careful diagnosis. In addition, Wnt/ $\beta$-catenin signal alteration may play a role in the pathogenesis of BCA and BCAC.
\end{abstract}

\section{Introduction}

Basal cell adenoma (BCA) is a benign tumor accounting for $1-3 \%$ of salivary gland epithelial tumors $[1,2]$, and is histologically characterized by basaloid cell proliferation in an anastomosing jigsaw puzzle-like solid or trabecular pattern with peripheral palisading [3]. Other kinds of salivary gland tumors with basal cell differentiation can share morphologic features with BCA. Such tumors include basal cell adenocarcinoma (BCAC), adenoid cystic carcinoma (ACC), and pleomorphic adenoma (PA). BCAC is the malignant counterpart to BCA, and has a relatively high recurrence rate but favorable prognosis [4-6]. BCA and ACC show similar histological appearance in terms of their focal or extensive cribriform structures $[7,8]$. ACC is generally indolent, but the long-term prognosis is poor due to persistent local recurrence and distant metastases. Thus, differential diagnosis of these tumors is clinically very important, but sometimes challenging. Precise diagnosis can be particularly difficult for cases in which only biopsy or other small samples are available for analysis.

Characteristic molecular abnormalities have been identified in salivary gland tumors. $\beta$-catenin is one of the canonical Wnt signaling pathway components regulating the expression of Wnt target genes. $\beta$ catenin is usually maintained at a low level in the cytoplasm due to phosphorylation by a multiprotein complex containing APC, Axin, GSK3 $\beta$ and PP2A. Mutations of CTNNB1, APC or AXIN result in nuclear $\beta$-catenin accumulation linked with abnormal activity of Wnt/ $\beta$-catenin signaling pathway [9], and play a role in the pathogenesis of various diseases [10-12]. Nuclear $\beta$-catenin expression is observed in most cases of BCA, and activating mutations of CTNNB1 have been identified

\footnotetext{
* Corresponding author.

E-mail address: oda@surgpath.med.kyushu-u.ac.jp (Y. Oda).
} 
in about half of BCAs [13-15]. However, the molecular mechanisms causing nuclear accumulation of $\beta$-catenin, other than CTNNB1 mutation, remain to be clarified. Although nuclear $\beta$-catenin expression has been reported in some cases of basal cell adenocarcinoma (BCAC), the pathogenesis of BCAC has been unclear [14].

As for ACC, MYB-NFIB fusion gene has been identified in approximately $60 \%$ to $70 \%$ of cases [16-19]. In a recent study, the presence of MYBL1 gene rearrangement was reported in about 25\% of ACCs without $M Y B$ gene rearrangement [20]. In a previous report about Wnt/ $\beta$-catenin signal alteration in ACC, mutations in CTNNB1, APC or AXIN1 were found in some populations of ACCs [21]. However, the relationship between gene rearrangement in MYB or MYBL1 and Wnt/ $\beta$-catenin signal alteration has not been clarified in ACC.

The aim of this study was to further elucidate the Wnt/B-catenin signal alterations in BCA and the diagnostic utility of these alterations in the differentiation between BCA and morphological mimics.

\section{Materials and methods}

\subsection{Case selection}

We examined 135 cases of salivary gland tumors, including BCA $(n=34)$, BCAC $(n=3)$, ACC $(n=67)$ and PA $(n=31)$. These cases were selected from the institutional database of Kyushu University Hospital and its affiliated hospitals, dating from 1983 to 2014. BCA, BCAC and PA occurred in parotid gland $(n=33, n=3$ and $n=22$, respectively) and submandibular gland $(\mathrm{n}=1, \mathrm{n}=0$ and $\mathrm{n}=9$, respectively). Forty-seven cases of ACC occurred in parotid gland $(n=9)$, submandibular gland $(n=13)$, sublingual gland $(n=3)$ and nasal/ paranasal cavity $(n=22)$. The remaining twenty cases occurred in other sites of head and neck (Table 1). This study was approved by the Institutional Review Boards of Kyushu University (no. 26-185, 29-200) and the National Kyushu Cancer Center (no. 2015-5).

\subsection{Immunohistochemical staining for $\beta$-catenin}

Immunohistochemical staining was performed using 4- $\mu \mathrm{m}$-thick, formalin-fixed, paraffin-embedded (FFPE) tissue sections and the primary antibodies for $\beta$-catenin (clone 14, mouse monoclonal; dilution $\times 200$; BD Biosciences, San Jose, CA). A biotin-free, horseradish peroxidase enzyme-labeled polymer method (EnVision + system; Dako, Carpinteria, CA) was used. All tissue sections were counterstained with hematoxylin.

We evaluated at least 500 cells in the hot spot, then assessed the

Table 1

Clinical data of BCA, BCAC, ACC and PA.

\begin{tabular}{lllll}
\hline & BCA & BCAC & ACC & PA \\
\cline { 2 - 5 } & $\mathrm{n}=34$ & $\mathrm{n}=3$ & $\mathrm{n}=67$ & $\mathrm{n}=31$ \\
\hline $\begin{array}{l}\text { Age (years) } \\
\text { Sex }\end{array}$ & $60(18-78)$ & $61(30-77)$ & $61(22-81)$ & $54(13-84)$ \\
$\quad \begin{array}{l}\text { Male } \\
\text { Female }\end{array}$ & $12(35.3 \%)$ & $1(33.3 \%)$ & $28(41.8 \%)$ & $8(25.8 \%)$ \\
$\begin{array}{l}\text { Site } \\
\text { Parotid gland }\end{array}$ & $22(64.7 \%)$ & $2(66.7 \%)$ & $39(58.2 \%)$ & $23(74.2 \%)$ \\
$\quad \begin{array}{l}\text { Submandibular gland } \\
\text { Sublingual gland } \\
\text { Nasal/Paranasal } \\
\quad \text { cavity }\end{array}$ & $1(2.9 \%)$ & & $9(13.4 \%)$ & $22(71.0 \%)$ \\
$\begin{array}{c}\text { Other head and neck } \\
\text { regions }\end{array}$ & & & $3(4.5 \%)$ & $9(29.0 \%)$ \\
$\quad$ & & & $22(32.8 \%)$ & \\
\end{tabular}

Abbreviation: BCA, basal cell adenoma; BCAC, basal cell adenocarcinoma; ACC, adenoid cystic carcinoma; PA, pleomorphic adenoma; M, male; F, female; N.A., not available data.

a The data are shown by median with the range in the parenthesis.

b Other head and neck regions include tongue $(n=7)$, palate $(n=1)$, orbit $(n=3)$, lacrimal duct $(n=2)$, external ear $(n=4)$, nasopharynx $(n=2)$ and trachea $(n=1)$. labeling index of nuclear immunoreactivity of $\beta$-catenin in neoplastic cells. We drew a ROC curve to calculate a cut-off value of the nuclear $\beta$ catenin labeling index for BCA compared with other tumors (BCAC, ACC and PA), and found that $3 \%$ was the most appropriate value (see Results).

\subsection{Mutational analysis for CTNNB1, APC and AXIN}

We extracted genomic DNA from FFPE tissue sections by using a QIAamp DNA Mini Kit (Qiagen, Hilden, Germany) according to the manufacturer's instructions. To detect mutations in CTNNB1 (exon3), APC (exon15), AXIN1 (exon5, 7, 10) and AXIN2 (exon1, 5, 7) [10], we performed a polymerase chain reaction (PCR) followed by Sanger sequencing, as previously described [22]. The primer sequences are summarized in Supplementary Table 1. The PCR products were subjected to $2 \%$ agarose gel electrophoresis, and the sequence was confirmed by the direct sequencing method using an ABI Prism 310 sequence analyzer (Applied Biosystems, Foster City, CA, USA).

\subsection{MYB and MYBL1 fluorescence in situ hybridization (FISH) and evaluation}

Fluorescence in situ hybridization (FISH) was done on FFPE tissue sections of ACC to detect MYB or MYBL1 gene rearrangements. We used commercially available break-apart probes for the MYB gene (MYB Split Dual Color FISH Probe; GSP Laboratory, Kobe, Japan) and MYBL1 gene (MYBL1 Split Dual Color FISH Probe; GSP Laboratory, Kobe, Japan) in accordance with the manufacturer's instructions. In the MYB FISH probe design, the $5^{\prime}$ MYB signal was labeled with spectrum green, and the $3^{\prime} M Y B$ signal was labeled with spectrum red. In the MYBL1 FISH probe design, the $5^{\prime} M Y B L 1$ signal was labeled with spectrum red, and the $3^{\prime}$ MYBL1 signal was labeled with spectrum green. The hybridized slides were reviewed on a fluorescent microscope (Olympus BX53; Olympus, Tokyo, Japan) under a $\times 100$ objective lens with oil immersion using a DAPI/Green/Red triple band-pass filter set. The results were scored by evaluating 100 non-overlapping tumor cells with hybridization signals. Tumor cells lacking hybridization signals were excluded from evaluation. A split signal was defined by $5^{\prime}$ and $3^{\prime}$ signals observed at a distance larger than the signal size, and signals separated by a distance smaller than the signal size were regarded as fused signals. When the ratio of tumor cells having split signals or isolated $5^{\prime}$ signals was more than $20 \%$, the samples was considered to be positive for gene rearrangement.

\subsection{Statistical analysis}

All calculations were done using JMP Statistical Discovery Software (version 11.0.0; SAS, Cary, NC). We used the Wilcoxon rank sum test to evaluate the comparisons between basal cell tumors and mimics. The results were considered significant when the p-value was $<0.05$.

\section{Results}

\subsection{Histological findings and immunohistochemical results for $\beta$-catenin}

BCA showed diverse histological appearances, including predominantly tubulotrabecular $(n=28)$ (Fig. 1A), cribriform $(n=1)$ (Fig. 1B), solid $(n=4)$ and membranous $(n=1)$ patterns. Among these 34 cases of BCA, 10 cases $(29.4 \%)$ had at least focally cribriform or membranous structure similar to ACC. In most BCAs $(n=32)$, strong nuclear $\beta$-catenin immunoreactivity was present in abluminal cells, but not in luminal cells (Fig. 1C). One case of membranous-type BCA with focal tubulotrabecular component showed nuclear $\beta$-catenin expression. Two cases without nuclear $\beta$-catenin expression were tubulotrabecular-type, but not membranous-type.

BCAC resembled BCA cytologically but exhibited infiltrative growth 

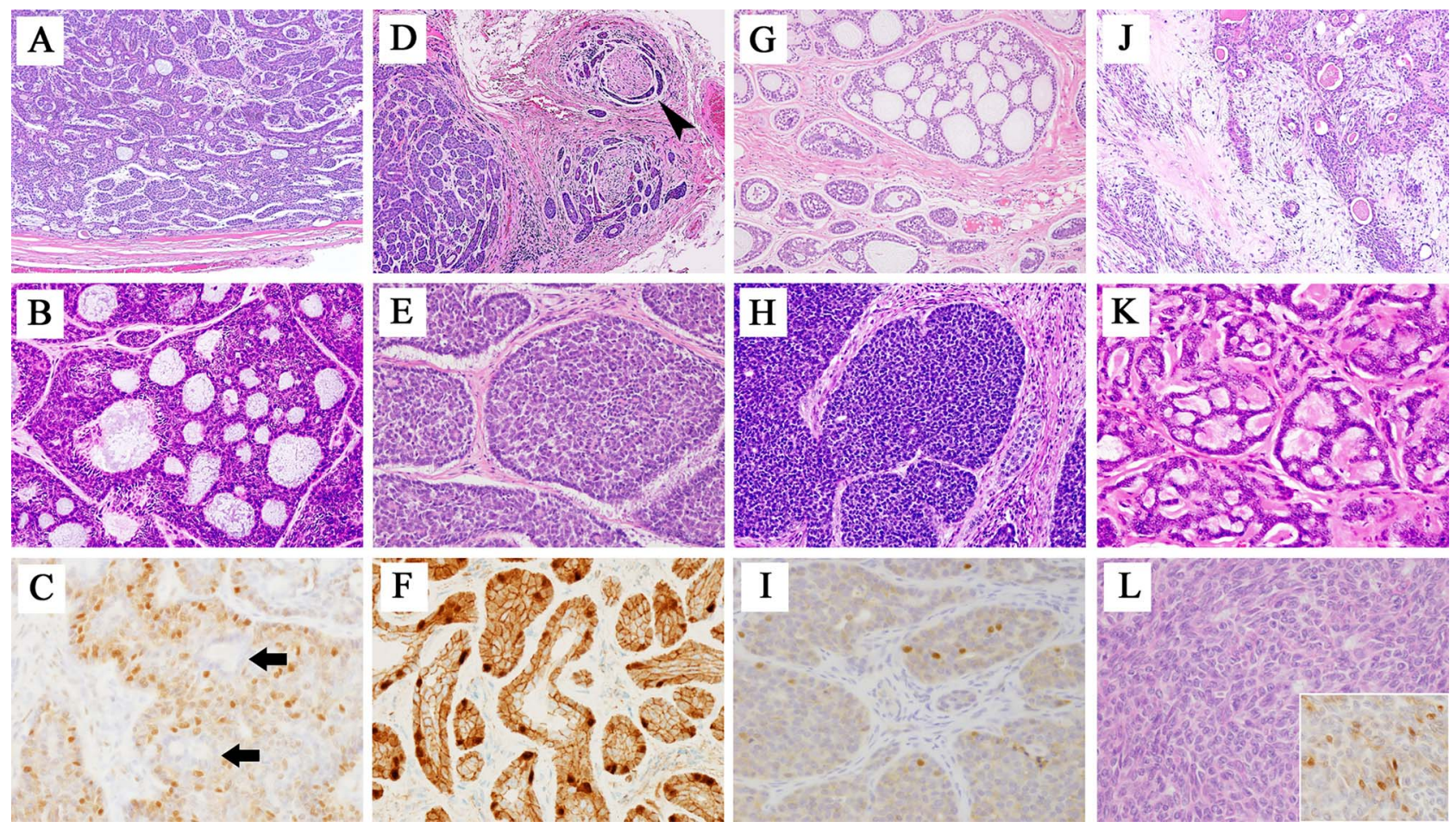

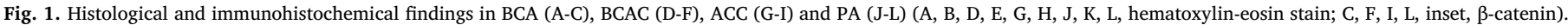

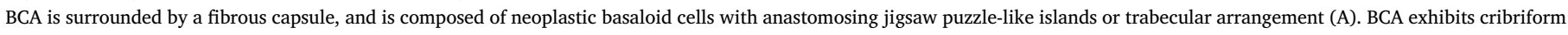

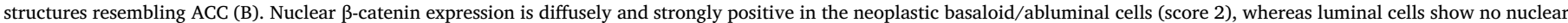

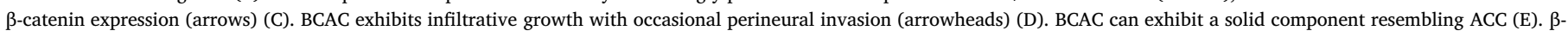

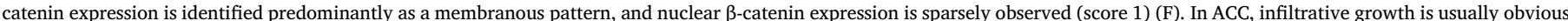

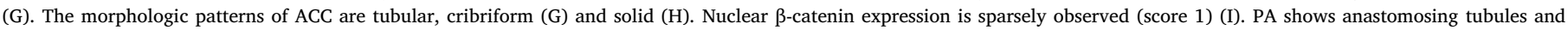

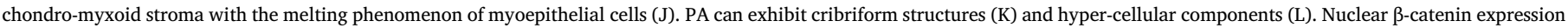

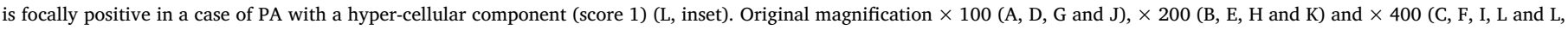
inset).

with a predominantly tubulotrabecular $(\mathrm{n}=1$ ) (Fig. 1D) or solid $(n=2)$ (Fig. 1E) pattern. In one case of BCAC, focal but strong staining for $\beta$-catenin expression was observed in the nuclei of abluminal cells (Fig. 1F).

ACC also exhibited infiltrative growth with a predominantly tubular $(n=26)$, cribriform $(n=34)$ (Fig. $1 \mathbf{G})$ or solid $(n=7)$ (Fig. $1 \mathbf{H})$ pattern. In a few cases of ACC, nuclear $\beta$-catenin expression was focal with weak-to-strong staining intensity in abluminal cells (Fig. 1I).

PA showed variable histological appearances such as predominantly chondro-myxoid matrix-rich $(\mathrm{n}=17)$ (Fig. $1 \mathbf{J})$ and hyper-cellular ( $n=14$ ) (Fig. 1L) patterns; 11 of 31 cases of PA had a cribriform structure focally resembling that of ACC $(n=2)$ (Fig. $1 \mathbf{K})$ or a peripheral palisading structure resembling that of BCA $(n=9)$. In one case of PA, focal nuclear $\beta$-catenin expression was observed in myoepithelial cells in the hyper-cellular component (Fig. 1L, inset).

To establish an optimal cut-off value, we assessed the labeling index of nuclear $\beta$-catenin-expressing cells in neoplastic cells. The distribution of the labeling index is illustrated in Figs. 2 and 3. The nuclear $\beta$-catenin labeling index ranged from $0 \%$ to $57 \%$ (median: $22.5 \%$; mean: $22.9 \%$ ) in BCA, from $0 \%$ to $8 \%$ (median: $0 \%$, mean: $2.6 \%$ ) in BCAC, from $0 \%$ to $10 \%$ (median: $0 \%$, mean: $0.4 \%$ ) in ACC and from $0 \%$ to $13 \%$ (median: 0\%, mean: 0.3\%) in PA. The nuclear $\beta$-catenin labeling index was significantly higher in BCA than BCAC, ACC or PA $(\mathrm{p}=0.0179$, $\mathrm{p}=<0.0001$ and $\mathrm{p}=<0.0001$, respectively) (Fig. 3). Of note, ten cases of BCA showed a cribriform or membranous structure where the nuclear $\beta$-catenin labeling index ranged from $13 \%$ to $45 \%$ (median: $31.0 \%$, mean: $29.9 \%$ ); the labeling index was significantly higher than that of ACC $(\mathrm{p}=<0.0001)$.

We then compared the ROC curve between BCA and non-BCA
(BCAC, ACC and PA). The results showed that the area under the curve (AUC) was 0.963 , and that a cut-off value $\geq 3 \%$ was most appropriate (Youden index $=0.891$ ) (Table 2 ). If the cut-off value was $\geq 3 \%$, the sensitivity and specificity for BCA were $94 \%$ and $95 \%$. Moreover, if the cut-off was $\geq 15 \%$, the specificity for BCA was $100 \%$, but the sensitivity declined to $76 \%$. Therefore, we used the following scoring system by labeling index: score 0 (negative): $0 \%$ to $<3 \%$; score 1 : $3 \%$ to $<15 \%$; score 2 : $\geq 15 \%$. Samples with a score of 1 or 2 were considered positive for nuclear $\beta$-catenin expression. Positivity for nuclear $\beta$-catenin expression was observed in $32 / 34$ cases $(94.1 \%)$ of BCA, $1 / 3$ cases (33.3\%) of BCAC, $3 / 67$ cases $(4.4 \%)$ of ACC and $1 / 31$ cases $(3.2 \%)$ of PA (Table 3).

\subsection{Mutation analysis for Wnt/ $\beta$-catenin signaling pathway}

Table 4 summarizes the results of mutation analysis. CTNNB1 (exon 3) missense mutations were present in $14 / 34$ cases $(41.1 \%)$ of BCA; almost all mutations caused residue I35 to be replaced with a T (I35T), and one mutation was T41P. Moreover, we detected APC (exon 15) missense mutations in $1 / 34$ cases (2.9\%) of BCA; these mutations were E1295 K and E1353 K. AXIN1 (exon 5) missense mutations were present in $3 / 34$ cases $(8.8 \%)$ of BCA; these mutations were G430E, P439S, G508D and G514R. We found no missense mutations in AXIN2 in BCAs. Collectively, $18 / 34$ cases (52.9\%) of BCA had missense mutations in either CTNNB1, APC or AXIN1. Among the 32 cases of BCA with nuclear $\beta$-catenin expression, 17 cases $(50 \%)$ had mutations in CTNNB1 or related genes. AXIN1 missense mutations were detected in 1 of 2 cases of BCA without nuclear $\beta$-catenin expression (Table 5 ).

CTNNB1 mutation (exon 3) was present in $1 / 3$ cases $(33.3 \%)$ of 


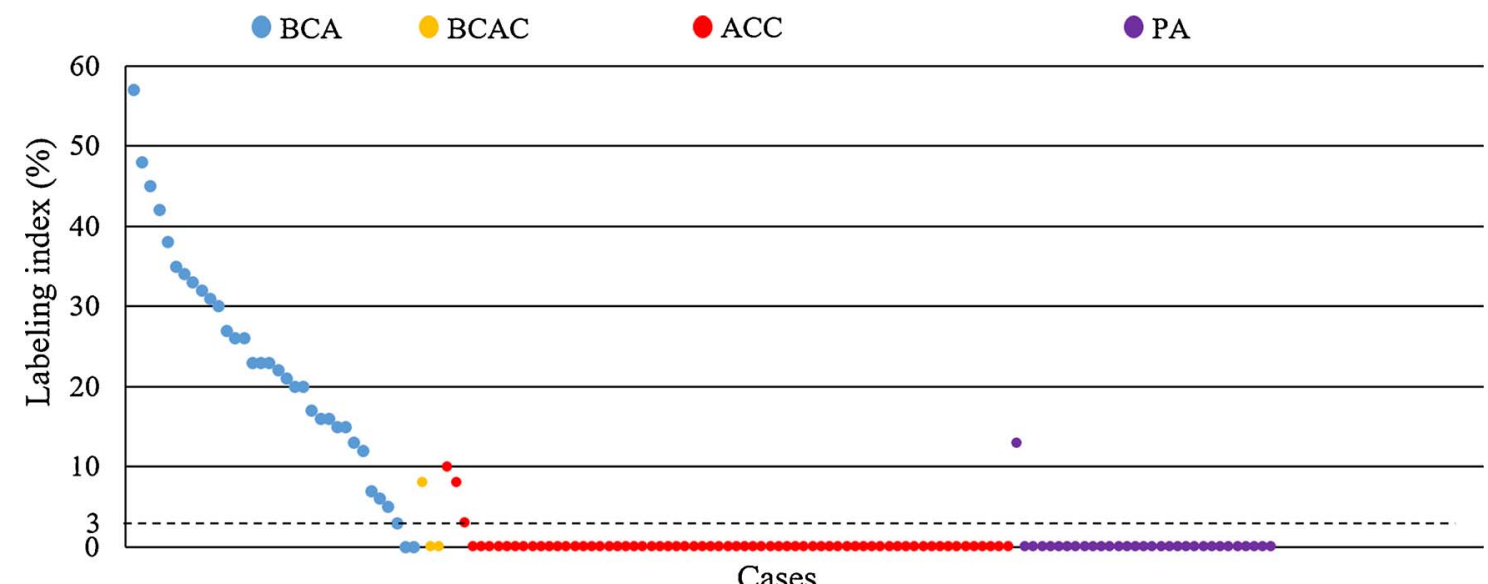

Cases

Fig. 2. Distribution of the nuclear $\beta$-catenin labeling index for BCA, BCAC, ACC and PA. The cut-off value (3\%) is shown by a dotted line.

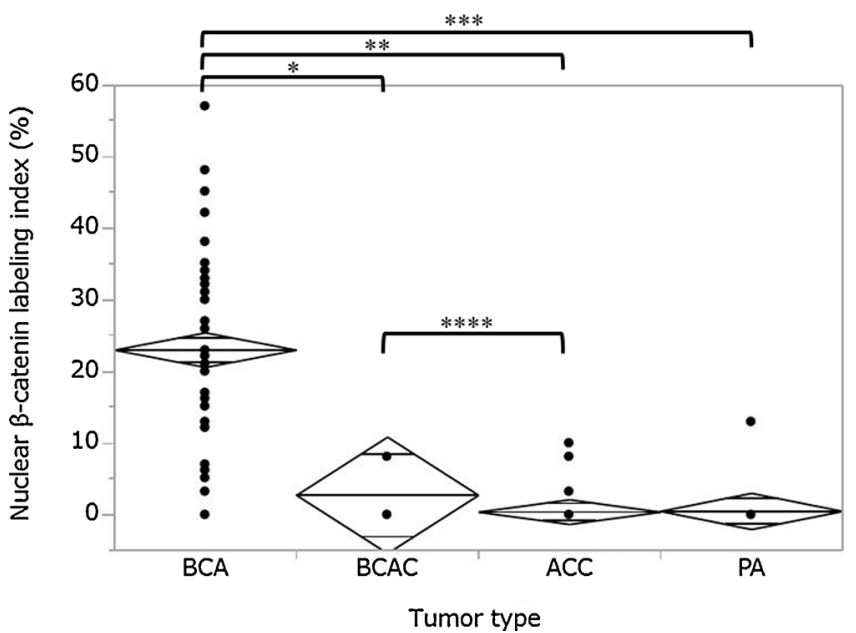

Fig. 3. Distribution of the nuclear $\beta$-catenin labeling index in BCA, BCAC, ACC and PA. The nuclear $\beta$-catenin labeling index of BCA is significantly higher than those in BCAC, ACC and PA $\left({ }^{*} \mathrm{p}=0.0179, * * \mathrm{p}=<0.0001, * * * \mathrm{p}=<0.0001\right.$, respectively). The nuclear $\beta$-catenin labeling index of BCAC is significantly higher than that in ACC $(* * * *$ $\mathrm{p}=0.0399)$.

Table 2

ROC analysis to determine the nuclear $\beta$-catenin positivity.

\begin{tabular}{llllll}
\hline Cut-off & $\begin{array}{l}\text { BCA } \\
(\mathrm{n}=34)\end{array}$ & $\begin{array}{l}\text { Non-BCA } \\
(\mathrm{n}=101)\end{array}$ & Sensitivity & Specificity & $\begin{array}{l}\text { Youden } \\
\text { index }\end{array}$ \\
\hline $3 \%$ & 32 & 5 & $94 \%$ & $95 \%$ & 0.891 \\
$5 \%$ & 31 & 4 & $91 \%$ & $96 \%$ & 0.872 \\
$10 \%$ & 28 & 2 & $82 \%$ & $98 \%$ & 0.803 \\
$15 \%$ & 26 & 0 & $76 \%$ & $100 \%$ & 0.764 \\
$20 \%$ & 21 & 0 & $61 \%$ & $100 \%$ & 0.617 \\
$30 \%$ & 11 & 0 & $32 \%$ & $100 \%$ & 0.323 \\
\hline
\end{tabular}

Abbreviation: ROC, receiver operating characteristic; BCA, basal cell adenoma.

${ }^{a}$ Non-BCA includes basal cell adenocarcinoma, adenoid cystic carcinoma and pleomorphic adenoma.

BCAC; this mutation was I35T. Nuclear $\beta$-catenin expression was detected in this case by IHC.

Both AXIN1 (exon7) and AXIN2 (exon 1) missense mutations were present in a single case of ACC (1/16 cases, $6.2 \%)$; AXIN1 mutation was H662Y, and AXIN2 mutations were G39R and G214E (Table 4). Nuclear $\beta$-catenin expression was detected in this case by IHC.

In a case of PA with nuclear $\beta$-catenin expression by IHC, no mutations were detected in $\mathrm{Wnt} / \beta$-catenin signal-related genes.

\subsection{MYB and MYBL1 gene rearrangements and Wnt/ $\beta$-catenin signaling pathway alteration in ACCs}

MYB FISH and MYBL1 FISH were successful in 58 cases of ACC. $M Y B$ and MYBL1 gene rearrangements were identified in 41/58 cases (70.6\%) and 2/58 cases (3.4\%) of ACCs, respectively (Fig. 4). Fifteen of 58 cases $(25.8 \%)$ were negative for both MYB and MYBL1 gene rearrangements. $M Y B$ and/or $M Y B L 1$ gene rearrangement could not be assessed in the remaining 9 cases due to weak FISH signals. Table 6 summarizes the molecular features in 3 cases of ACC with nuclear $\beta$ catenin expression. All 3 cases had either MYB or MYBL1 gene rearrangement, and one case (Case 1) had AXIN1 and AXIN2 mutations.

\section{Discussion}

Differential diagnosis among BCA and other salivary gland tumors with basal cell differentiation (BCAC, ACC and PA) is sometimes challenging due to their similar histological appearance. In several recent studies, nuclear $\beta$-catenin immunoreactivity was observed exclusively in BCA and BCAC (Table 7) [13-15]. For example, Kawahara et al. defined $\geq 1 \%$ as positive for nuclear $\beta$-catenin immunoreactivity, and found nuclear $\beta$-catenin expression in $21 / 22$ cases (95.4\%) of BCA and $1 / 3$ cases $(33.3 \%)$ of BCAC [13]. Similarly, Jo et al. showed that nuclear $\beta$-catenin expression was observed in $18 / 22$ cases $(81.8 \%)$ of BCA and in $2 / 3$ cases $(66.6 \%)$ of BCAC [14]. Jung et al. used $5 \%$ as the cutoff value, and reported that nuclear $\beta$-catenin expression was present in $17 / 20$ cases (85\%) of BCA, and in all cases of BCAC (7/7 cases) [15]. Although different clones of antibodies were used in these previous reports and the current study, the prevalence of nuclear $\beta$-catenin immunoreactivity was essentially similar among the study cohorts. Meanwhile, nuclear $\beta$-catenin immunoreactivity was observed in $0 / 37$ cases $(0 \%)$ of ACC and $0 / 63$ cases $(0 \%)$ of PA (Table 7) $[13,14]$. In contrast, Daa et al. detected nuclear $\beta$-catenin expression in $2 / 20$ cases (10\%) of ACC [21]. One possible explanation for this discrepancy is that there have been no standard criteria for nuclear $\beta$-catenin expression. In the current study, the vast majority of BCA and one third of BCACs were positive for nuclear $\beta$-catenin expression, whereas a minor subset of ACCs and PAs showed variable levels of nuclear $\beta$-catenin immunoreactivity. To establish useful criteria of nuclear $\beta$-catenin positivity for use in pathological diagnosis, we assessed a labeling index of nuclear $\beta$-catenin immunoreactivity and found that a labeling index of $\geq 3 \%$ was a reasonable cut-off value with $94 \%$ sensitivity and $95 \%$ specificity (Table 2). With this cut-off value, nuclear $\beta$-catenin expression was positive in $32 / 34$ cases $(94.1 \%)$ of BCA and 5/101 cases (4.9\%) of non-BCA tumors. Furthermore, when the cut-off for nuclear $\beta$-catenin positivity was designated as $\geq 15 \%$ (score 2 ), the specificity 
Table 3

Nuclear expression of $\beta$-catenin in BCA, BCAC, ACC and PA.

\begin{tabular}{|c|c|c|c|c|c|}
\hline & \multicolumn{4}{|c|}{ Nuclear $\beta$-catenin expression } & \multirow{2}{*}{$\frac{\text { Labeling index }^{\mathrm{a}}}{\text { Mean +SD (\%) }}$} \\
\hline & Score 0 & Score 1 & Score 2 & Score $1+2$ (Positive, total) & \\
\hline BCA $(n=34)$ & $2(5.8 \%)$ & $6(17.6 \%)$ & $26(76.4 \%)$ & $32(94.1 \%)$ & $22.9+1.2(0-57)$ \\
\hline $\operatorname{BCAC}(n=3)$ & $2(66.6 \%)$ & $1(33.3 \%)$ & 0 & $1(33.3 \%)$ & $2.6+1.2(0-8)$ \\
\hline $\operatorname{ACC}(n=67)$ & $64(95.5 \%)$ & $3(4.4 \%)$ & 0 & $3(4.4 \%)$ & $0.4+1.2(0-10)$ \\
\hline $\mathrm{PA}(\mathrm{n}=31)$ & $30(96.7 \%)$ & $1(3.2 \%)$ & 0 & $1(3.2 \%)$ & $0.3+0.8(0-13)$ \\
\hline
\end{tabular}

${ }^{\text {a }}$ The data are shown by mean $+\mathrm{SD}$ with the range in the parenthesis.

Table 4

Mutations of Wnt/ $\beta$-catenin-related genes in BCA, BCAC, ACC and PA.

\begin{tabular}{lllll}
\hline & CTNNB1 & APC & AXIN1 & AXIN2 \\
\hline BCA $(\mathrm{n}=34)$ & $14(41.1 \%)$ & $1(2.9 \%)$ & $3(8.8 \%)$ & 0 \\
BCAC $(\mathrm{n}=3)$ & $1(33.3 \%)$ & 0 & 0 & 0 \\
ACC $(\mathrm{n}=16)^{\mathrm{a}}$ & 0 & 0 & $1(6.2 \%)$ & $1(6.2 \%)$ \\
PA $(\mathrm{n}=1)^{\mathrm{b}}$ & 0 & 0 & 0 & 0 \\
\hline
\end{tabular}

Table 5

Prevalence of nuclear $\beta$-catenin expression and Wnt/ $\beta$-catenin - related gene mutations in BCAs.

\begin{tabular}{|c|c|c|c|}
\hline & & \multicolumn{2}{|c|}{$\begin{array}{l}\text { Mutations in CTNNB1, APC, AXN1 and } \\
\text { AXIN2 }\end{array}$} \\
\hline & & $+(\mathrm{n}=18)$ & $-(\mathrm{n}=16)$ \\
\hline \multirow{2}{*}{$\begin{array}{l}\text { Nuclear } \beta \text {-catenin } \\
\text { expression }\end{array}$} & $+(\mathrm{n}=32)$ & $17(50.0 \%)$ & $15(44.1 \%)$ \\
\hline & $-(\mathrm{n}=2)$ & $1(2.9 \%)$ & $1(2.9 \%)$ \\
\hline
\end{tabular}

Percentages in parentheses are relative to total cases $(n=34)$ of BCAs.

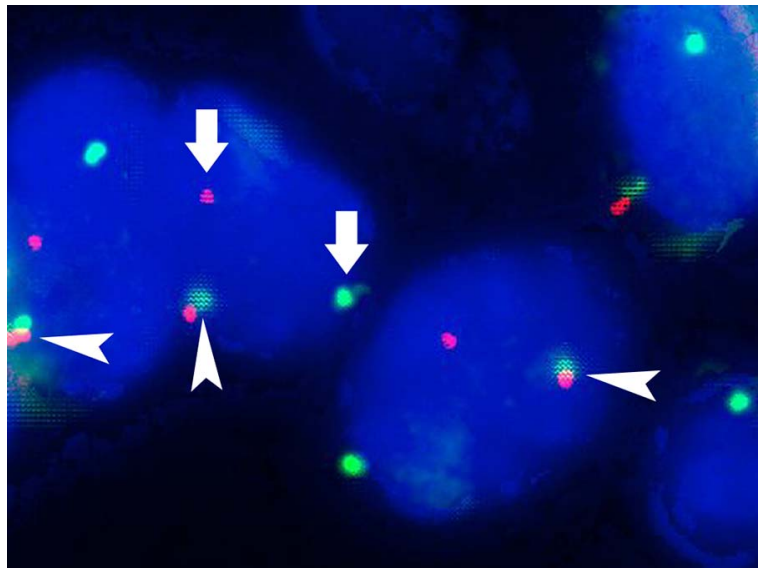

Fig. 4. Split FISH for $M Y B$ rearrangement in ACC (Original magnification $\times 1000$ ). Tumor cells show a split (separated) signal pattern of one green and one red (arrow). The intact MYB is shown by a fused (yellow) signal or closely juxtaposed red and green signals (arrowhead).

for BCA was $100 \%$, but the sensitivity fell to $76 \%$. Therefore, when the $\beta$-catenin labeling index is $3-14 \%$ (score 1 ), careful diagnosis is needed to avoid confusion between BCA and other tumors with basal cell differentiation. In our study, 10/34 cases (29.4\%) of BCA had at least focally cribriform or membranous structure similar to ACC, and the $\beta$ catenin labeling index was score $2(\geq 15 \%)$ in the vast majority of these BCAs. On the other hand, in all cases of ACC, the $\beta$-catenin labeling index was lower than $15 \%$. Therefore, when the $\beta$-catenin labeling index exceeds $15 \%$ in a morphologically challenging case with a cribriform or membranous structure, the case is more likely to be BCA.

According to the previous studies [13-15], CTNNB1 mutations have
Table 6

Molecular features of ACCs with aberrant nuclear $\beta$-catenin expression.

\begin{tabular}{|c|c|c|c|c|c|}
\hline Case & Site & $\begin{array}{l}\text { Histological } \\
\text { subtype }\end{array}$ & $\begin{array}{l}\text { Nuclear } \beta \text { - } \\
\text { catenin } \\
\text { labeling } \\
\text { index }\end{array}$ & $\begin{array}{l}\text { MYB, } \\
\text { MYBL1 } \\
\text { FISH }\end{array}$ & $\begin{array}{l}\text { Mutations in } \\
\text { Wnt/ß- } \\
\text { catenin- } \\
\text { related genes }\end{array}$ \\
\hline Case 1 & Maxilla & Cribriform & $10 \%$ &,$+ M Y B$ & $\begin{array}{l}+(A X I N 1 \text { and } \\
\text { AXIN2) }\end{array}$ \\
\hline Case 2 & Maxilla & Cribriform & $8 \%$ &,$+ M Y B$ & - \\
\hline Case 3 & Nasal cavity & Solid & $3 \%$ & $\begin{array}{l}+ \\
M Y B L 1\end{array}$ & - \\
\hline
\end{tabular}

Abbreviation: FISH, fluorescence in situ hybridization.

been detected in about half of the cases of BCA (Fig. 5), but the reason for the discrepancy between the frequency of nuclear $\beta$-catenin immunoreactivity and the prevalence of CTNNB1 mutation has been unclear. In our series, CTNNB1 missense mutations were identified in about $40 \%$ of BCAs; this result was consistent with the previous reports [13-15]. Moreover, interestingly, 4/34 cases (11.7\%) of BCA showed APC and AXIN1 missense mutations. Collectively, CTNNB1, APC and AXIN1 missense mutations were detected in $18 / 34$ cases $(52.9 \%)$ of $\mathrm{BCA}$. To the best of our knowledge, the present study is the first report showing the prevalence of Wnt/ $\beta$-catenin signaling pathway alterations including CTNNB1, APC, AXIN1 and AXIN2 in BCA. Our result suggests that $A P C$ and AXIN1 alterations, as well as CTNNB1 mutation, may be responsible for the accumulation of $\beta$-catenin in BCA. However, these mutations could not account for the nuclear $\beta$-catenin accumulation in about $40 \%$ of BCA cases, and thus alternative molecular mechanisms will be needed to explain the nuclear $\beta$-catenin accumulation in these tumors. As one of the possible mechanisms, the methylation of Wntsuppressing genes such as SFER, WIF1 and DKK1 could be a cause of nuclear $\beta$-catenin expression; this alteration has been reported in colorectal cancer [23-25].

In the current study, we found that nuclear $\beta$-catenin expression was also present in a certain percentage of the cases of BCAC, ACC and PA, in addition to gene mutations in CTNNB1, AXIN1 or AXIN2. In BCAC, the molecular alterations that underlie the development and progression of the tumor are poorly characterized. Some of the previous studies reported that none of BCACs had CTNNB1 mutation, despite the presence of nuclear $\beta$-catenin expression in $33-100 \%$ of cases (Fig. 5) [13-15]. In our series, $1 / 3$ cases (33.3\%) of BCAC showed focal nuclear $\beta$-catenin expression in addition to CTNNB1 mutation. This genetic commonality suggests that at least some cases of BCAC might develop via malignant transformation from BCA. Recently, Jo et al. reported that one case of BCAC with a focal membranous component had PIK3CA mutation, biallelic inactivation of NFKBIA (coding IкB $\alpha$ ) and focal CYLD deletion, but not CTNNB1 mutation, despite the finding of focal nuclear $\beta$-catenin expression [14]. Although Choi et al. reported the loss of heterozygosity ( $\mathrm{LOH}$ ) of CYLD in $17 / 21$ (80.9\%) cases of sporadic membranous-type BCAs (dermal analogue tumor of salivary gland) [26], CYLD loss was not observed in conventional BCAs in the study by Jo et al. [14]. In our series, one case of membranous-type BCA with focal tubulotrabecular component showed nuclear $\beta$-catenin 
Table 7

Nuclear $\beta$-catenin immunoreactivity in BCA, BCAC, ACC and PA in the previous reports and current study.

\begin{tabular}{|c|c|c|c|c|c|c|c|}
\hline Authors & Clone & Dilution & Cut-off & BCA & BCAC & ACC & PA \\
\hline Kawahara A, et al $^{\#}$ [13] & $\begin{array}{l}\beta \text {-catenin-1 } \\
\text { Mouse monoclonal } \\
\text { Dako Cytomatin }\end{array}$ & 1: 200 & $1 \%$ & $\begin{array}{l}21 / 22 \\
(95.4 \%)\end{array}$ & $\begin{array}{l}1 / 3 \\
(33.3 \%)\end{array}$ & $\begin{array}{l}0 / 17 \\
(0 \%)\end{array}$ & $\begin{array}{l}0 / 43 \\
(0 \%)\end{array}$ \\
\hline $\mathrm{Jo}_{\text {, et }} \mathrm{al}^{\#}[14]$ & $\begin{array}{l}14 \\
\text { Mouse monoclonal } \\
\text { BD Biosciences }\end{array}$ & 1: 1000 & $1 \%$ & $\begin{array}{l}18 / 22 \\
(81.8 \%)\end{array}$ & $\begin{array}{l}2 / 3 \\
(66.6 \%)\end{array}$ & $\begin{array}{l}0 / 20 \\
(0 \%)\end{array}$ & $\begin{array}{l}0 / 20 \\
(0 \%)\end{array}$ \\
\hline Jung, et $\mathrm{al}^{\#}[15]$ & $\begin{array}{l}\text { CAT-5H10 } \\
\text { Mouse monoclonal } \\
\text { Zymed Laboratories }\end{array}$ & 1: 2000 & $5 \%$ & $\begin{array}{l}17 / 20 \\
(85 \%)^{*}\end{array}$ & $\begin{array}{l}7 / 7 \\
(100 \%)\end{array}$ & N.D. & N.D. \\
\hline Daa $\mathrm{T}$, et $\mathrm{al}^{\#}[21]$ & $\begin{array}{l}17 \mathrm{C} 2 \\
\text { Mouse monoclonal } \\
\text { Novocastra Laboratories Ltd }\end{array}$ & 1: 100 & Not shown & N.D. & N.D. & $\begin{array}{l}2 / 20 \\
(10 \%)\end{array}$ & N.D. \\
\hline Our study & $\begin{array}{l}14 \\
\text { Mouse monoclonal } \\
\text { BD Biosciences }\end{array}$ & $1: 200$ & $3 \%$ & $\begin{array}{l}32 / 34 \\
(94.1 \%)\end{array}$ & $\begin{array}{l}1 / 3 \\
(33.3 \%)\end{array}$ & $\begin{array}{l}3 / 67 \\
(4.4 \%)\end{array}$ & $\begin{array}{l}1 / 31 \\
(3.2 \%)\end{array}$ \\
\hline
\end{tabular}

Abbreviation: N.D., not done.

* Nuclear $\beta$-catenin expression was present in all conventional BCAs (10/10) and 70\% (7/10) of tumors classified as "BCA with capsular invasion" (but not infiltrative growth).

expression. These findings suggest a diversity of molecular abnormality of membranous-type BCA. NFKBIA and CYLD are negative regulators of $\mathrm{NF}-\mathrm{\kappa B}$ signaling pathway, and dysfunctional alterations in these genes result in transcriptional up-regulation of target genes, leading to cell proliferation and survival $[27,28]$. Further analysis with a large number of BCAC cases is needed to elucidate the molecular tumorigenic mechanism and genetic relationship with BCA.

As for ACC, most previous reports have revealed that there is no nuclear $\beta$-catenin expression. According to the whole genome and exome sequencing data in ACCs, Wnt/ $\beta$-catenin signal alterations were detected in only 3 of 88 cases (3.4\%) in total; those alterations included homozygous loss, nonsynonymous mutation or truncation in CTNNB1 gene $[29,30]$. In our series, 3 cases $(4.4 \%)$ of ACC showed nuclear $\beta$ catenin expression, and one of them had AXIN1 and AXIN 2 mutations. Our results thus support the idea that only a minor subset of ACCs will exhibit nuclear $\beta$-catenin expression, in rare cases with $\mathrm{Wnt} / \beta$-cateninrelated gene alterations.

Here, the fact that nuclear $\beta$-catenin expression was present in ACC may evoke a diagnostic dilemma. In our study, all 3 cases of $\beta$-cateninpositive ACC had either MYB or MYBL1 gene rearrangement. Therefore, our data suggest that the combination of nuclear $\beta$-catenin immunochemistry and $M Y B$ and MYBL1 FISH may be helpful for differential diagnosis between BCA and ACC.

In $\mathrm{PA}$, only 1 of 31 cases $(3.2 \%)$ revealed nuclear $\beta$-catenin expression in neoplastic myoepithelial cells $(\mathrm{S}-100+, \alpha$-SMA + , calponin + ) of the hyper-cellular component, but this case had no mutation in Wnt/ $\beta$-catenin-related genes. Like, several publications have reported that nuclear $\beta$-catenin expression was not observed in PA (Table 7) $[13,14,31,32]$. It is well known that rearrangement of PLAG1 or HMGA2 genes is frequently present in PA $[33,34]$. Queimado et al. detected HMGA2-WIF1 fusion gene in a subset of PAs, and these PA cases showed lower expression of WIF1 (Wnt inhibitor factor 1) protein than normal salivary gland tissue [34]. WIF1 binds to WNT1 proteins and prevents Wnt signal activation [35]. Queimado et al. suggested that Wnt signal activation due to WIF1 downregulation might play a role in the development of PA [34], although the molecular mechanism of WIF1 downregulation was not detailed in their study.

LEF-1 is a nuclear transcription factor of Wnt/ $\beta$-catenin signal pathway. Recently, Bilodeau EA et al. reported that coexpression of LEF-1 and nuclear $\beta$-catenin was present in basaloid salivary gland tumors and various odontogenic tumors [36]. As a diagnostic marker, the authors suggested that LEF-1 expression may be helpful to distinguish BCA and BCAC from other salivary gland tumor.

In conclusion, our results suggest that nuclear $\beta$-catenin immunoreactivity with appropriate criteria may be useful to distinguish BCA from morphologically similar salivary gland tumors, although pathologists should pay attention to unexpected nuclear $\beta$-catenin expression in a minor subset of ACCs. In addition to previously reported CTNNB1 mutation in BCA, we revealed APC and AXIN1 mutations in some population of BCAs and CTNNB1 mutation in BCAC. These alterations in Wnt/ $\beta$-catenin signaling pathway may play a role in the pathogenesis of BCA and BCAC.

\section{B. Basal cell adenocarcinoma (BCAC)}

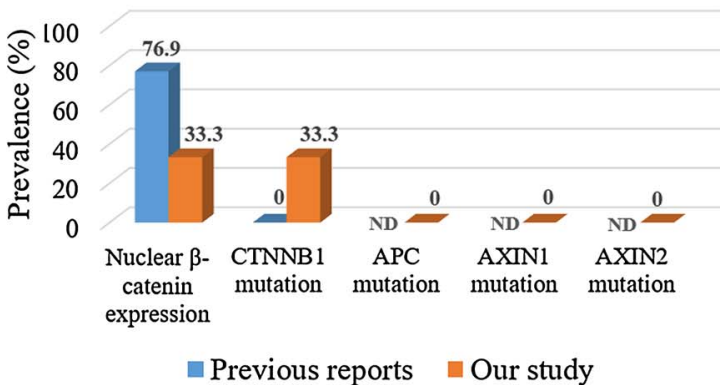

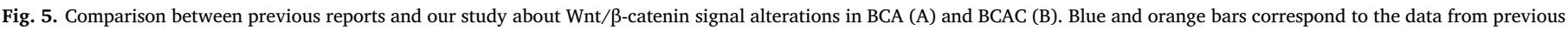

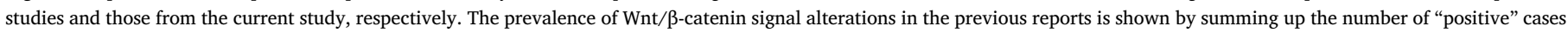
in the three studies [13-15] included in Table 7. Abbreviation: N.D., not done. 


\section{Funding}

The authors have no funding support to this article.

\section{Competing interests}

The authors declare that there are no potential conflicts of interest.

\section{Ethics approval}

This study was approved by the Ethics Committees of Kyushu University (no. 26-185, 29-100) and the National Kyushu Cancer Center (no. 2015-5).

\section{Acknowledgments}

We appreciate the technical support from the Research Support Center, Graduate School of Medical Science, Kyushu University. The English usage in this article was reviewed by KN International (http:// www.kninter.com/).

\section{Appendix A. Supplementary data}

Supplementary data associated with this article can be found, in the online version, at https://doi.org/10.1016/j.prp.2017.12.016.

\section{References}

[1] J. Li, I. Fonseca, Basal cell adenoma, in: A.K. El-Naggar, J.K. Chan (Eds.), WHO Classification of Head and Neck Tumors, fourth ed., IARC, Lyon, 2017, pp. 187-188.

[2] G.L. Ellis, P.L. Auclair, Tumor of the Salivary Glands, Atlas of Tumor Pathology, Fourth Series, Fascicle 9. AFIP, Washington, DC, 2008, pp. 71-85.

[3] J.K. Chan, W. Cheuk, Tumors of the salivary glands, in: C.D. Fletcher (Ed.), Diagnostic Histopathology of Tumors, Fourth Ed, ELSEVIER SAUNDERS, PA, 2013, pp. 288-292.

[4] S. Muller, L. Barnes, Basal cell adenocarcinoma of the salivary glands, Report of seven cases and review of the literature, Cancer 78 (1996) 2471-2477.

[5] G.L. Ellis, J.G. Wiscovitch, Basal cell adenocarcinomas of the major salivary glands, Oral Surg. Oral Med. Oral Pathol. 69 (1990) 461-469.

[6] T. Nagao, I. Sugano, Y. Ishida, et al., Basal cell adenocarcinoma of the salivary glands: comparison with basal cell adenoma through assessment of cell proliferation, apoptosis, and expression of p53 and bcl-2, Cancer 82 (1998) 439-447.

[7] Z. Tian, Y. Hu, L. Wang, et al., An unusual cribriform variant of salivary basal cell tumors: a clinicopathological study of 22 cases, Histopathology 61 (2012) 921-929.

[8] B.B. Li, C.X. Zhou, S.N. Jia, Basal cell adenoma of salivary glands with a focal cribriform pattern: clinicopathologic and immunohistochemical study of 19 cases of a potential pitfall for diagnosis, Ann. Diagn. Pathol. 18 (2014) 5-9.

[9] A. Kikuchi, Tumor formation by genetic mutations in the components of the Wnt signaling pathway, Cancer Sci. 94 (200) (2016) 225-229.

[10] Y. Hidaka, H. Mitomi, T. Saito, et al., Alteration in the Wnt/ $\beta$-catenin signaling pathway in gastric neoplasias of fundic gland (chief cell predominant) type, Hum. Pathol. 44 (2013) 2438-2448.

[11] R. Nomura, T. Saito, H. Mitomi, et al, GNAS mutation as an alternative mechanism of activation of the Wnt/ $\beta$-catenin signaling pathway in gastric adenocarcinoma of the fundic gland type, Hum. Pathol. 45 (2014) 2488-2496.

[12] W. Liu, X. Dong, M. Mai, et al, Mutations in AXIN2 cause colorectal cancer with defective mismatch repair by activating beta-catenin/TCF signaling, Nat. Genet. 26 (2000) 146-147.

[13] A. Kawahara, H. Harada, H. Abe, et al., Nuclear beta-catenin expression in basal cell adenomas of salivary gland, J. Oral Pathol. Med. 40 (2011) 460-466.

[14] V.Y. Jo, L.M. Sholl, J.F. Krane, et al., Distinctive patterns of CTNNB1 ( $\beta$-catenin) alterations in salivary gland basal cell adenoma and basal cell adenocarcinoma, Am J. Surg. Pathol. 40 (2016) 1143-1150.

[15] M.J. Jung, J.L. Roh, S.H. Choi, et al., Basal cell adenocarcinoma of the salivary gland: a morphological and immunohistochemical comparison with basal cell adenoma with and without capsular invasion, Diagn. Pathol. 8 (2013) 171.

[16] A. Nordkvist, J. Mark, H. Gustafsson, et al., Non-random chromosome rearrange ments in adenoid cystic carcinoma of the salivary glands, Genes. Chromosomes Cancer 10 (1994) 115-121.

[17] L.B. Brill II, W.A. Kanner, A. Fehr, et al., Analysis of MYB expression and MYB-NFIB gene fusions in adenoid cystic carcinoma and other salivary neoplasms, Mod. Pathol. 24 (2011) 1169-1176.

[18] Y. Mitani, J. Li, P.H. Rao, et al., Comprehensive analysis of the MYB-NFIB gene fusion in salivary adenoid cystic carcinoma: incidence, variability and clinicopathologic significance, Clin. Cancer Res. 16 (2010) 4722-4731.

[19] M. Persson, Y. Andren, J. Mark, et al., Recurrent fusion of MYB and NFIB transcription factor genes in carcinomas of the breast and head and neck, Proc. Natl. Acad. Sci. U. S. A. 106 (2009) 18740-18744.

[20] Y. Mitani, B. Liu, P.H. Rao, et al., Novel MYBL1 gene rearrangements with recurren MYBL1-NFIB fusions in salivary adenoid cystic carcinomas lacking $t(6 ; 9)$ translocations, Clin. Cancer Res. 22 (2016) 725-733.

[21] T. Daa, K. Kashima, N. Kaku, et al., Mutations in components of the Wnt signaling pathway in adenoid cystic carcinoma, Mod. Pathol. 17 (2004) 1475-1482.

[22] T. Nakano, H. Yamamoto, K. Hashimoto, et al., HER2 and EGFR gene copy number alterations are predominant in high-grade salivary mucoepidermoid carcinoma irrespective of MAML2 fusion status, Histopathology 63 (2013) 378-392.

[23] H. Suzuki, D.N. Watkins, K.W. Jair, et al., Epigenetic inactivation of SFRP genes allows constitutive WNT signaling in colorectal cancer, Nat. Genet. 36 (2004) 417-422.

[24] B. He, N. Reguart, L. You, et al., Blockade of Wnt-1 signaling induces apoptosis in human colorectal cancer cells containing downstream mutations, Oncogene 24 (2005) 3054-3058

[25] O. Aguilera, M.F. Fraga, E. Ballestar, et al., Epigenetic inactivation of the Wnt antagonist DICKKOPF-1 (DKK-1) gene in human colorectal cancer, Oncogene (2006) 4116-4121.

[26] H.R. Choi, J.G. Batsakis, D.L. Callender, et al., Molecular analysis of chromosome $16 \mathrm{q}$ regions in dermal analogue tumors of salivary glands: a genetic link to dermal cylindroma? Am. J. Surg. Pathol. 26 (2002) 778-783.

[27] G. Courtois, T.D. Gilmore, Mutations in the NF-kappaB signaling pathway: implications for human disease, Oncogene 25 (2006) 6831-6843.

[28] S.C. Sun, CYLD: a tumor suppressor deubiquitinase regulating NF-kappaB activation and diverse biological processes, Cell Death Differ. 17 (2010) 25-34.

[29] A.S. Ho, K. Kannan, D.M. Roy, et al., The mutational landscape of adenoid cystic carcinoma, Nat. Genet. 45 (2013) 791-798.

[30] J.S. Ross, K. Wang, J.V. Rand, et al., Comprehensive genomic profiling of relapsed and metastatic adenoid cystic carcinomas by next-generation sequencing reveals potential new routes to targeted therapies, Am. J. Surg. Pathol. 38 (2014) 235-238.

[31] C. Furuse, P.R. Cury, A. Altemani, et al., $\beta$-catenin and E-cadherin expression in salivary gland tumors, Int. J. Surg. Pathol. 14 (2006) 212-217.

[32] R.F. do Prado, A. Consolaro, L.A. Taveira, Expression of $\beta$-catenin in carcinoma in pleomorphic adenoma, pleomorphic adenoma and normal salivary gland: an immunohistochemical study, Med. Oral Patol. Oral Cir. Bucal. 11 (2006) 247-251.

[33] J. Kandasamy, A. Smith, S. Diaz, et al., Heterogeneity of PLAG1 gene rearrangements in pleomorphic adenoma, Cancer Genet. Cytogenet. 177 (2007) 1-5.

[34] L. Queimado, C.S. Lopes, A.M. Reis, WIF1, an inhibitor of the Wnt pathway, is rearranged in salivary gland tumors, Genes. Chromosomes Cancer 46 (2007) 215-225.

[35] J.C. Hsieh, L. Kodjabachian, M.L. Rebbert, et al., A new secreted protein that binds to Wnt proteins and inhibits their activities, Nature 398 (1999) 431-436.

[36] E.A. Bilodeau, M. Acquafondata, E.L. Barnes, et al., A comparative analysis of LEF-1 in odontogenic and salivary tumors, Hum. Pathol. 46 (2015) 255-259. 